\title{
The use of nitriding to enhance wear resistance of cast irons
}

\author{
Z. Yang ${ }^{1}$, D. O. Northwood ${ }^{1}$, X. Sun ${ }^{2}$, R. Lumbreras ${ }^{3}$, \\ G. C. Barber ${ }^{3}$ \& Q. Zou ${ }^{3}$ \\ ${ }^{1}$ Mechanical, Automotive and Materials Engineering, \\ University of Windsor, Canada \\ ${ }^{2}$ Chrysler LLC Tech Center, USA \\ ${ }^{3}$ Mechanical Engineering, Oakland University, USA
}

\begin{abstract}
This research is focused on using nitriding to enhance the wear resistance of austempered ductile iron (ADI), ductile iron (DI), and gray iron (GI). Three gas nitriding processes, namely "Gas nitriding + nitrogen cooled down to $800^{\circ} \mathrm{F}$ " (Blue), "Gas nitriding + cooled down to $300^{\circ} \mathrm{F}$ " (Gray), and "Gas nitriding + oil quenched" (Oil) were used. This study was carried out through optical metallography, roughness measurements, microhardness, and SEM. The ball-ondisc wear tests were conducted under lubricated conditions. It was found that COF for all materials in all nitrided conditions was small $(<0.045)$. The best wear performance was seen for ADI processed using the Gray and Oil gas nitriding processes. These processes produced a compound layer thickness of 4$6 \mu \mathrm{m}$, a low surface roughness $(0.8-1.3 \mu \mathrm{m}, \mathrm{Ra})$ and a high surface microhardness (1800-2200 HV). The wear rate decreased with increasing surface microhardness and decreasing surface roughness.
\end{abstract}

Keywords: cast irons, ADI, DI, GI, nitriding, wear.

\section{Introduction}

Cast irons have played an important role in human history. They are ferrous alloys with carbon contents higher than $2.1 \%$, silicon and often other alloying elements. Generally, they are divided into the following basic types: White Iron, Gray Iron, Ductile Iron, and Malleable Iron [1]. They are widely used in the 
automotive industry for applications such as fly-wheels, cylinders, camshafts, gears, and rolls [2-4].

Nitriding is one of the most popular methods for surface engineering. It is a low-temperature heat treating process that diffuses nitrogen into the surface of a metal to create a hardened surface. Nitriding is predominantly used on steel, but also cast irons, aluminum and titanium. Nitrided steels are widely used due to their superior hardness and attractive surface hardness, fatigue life, and tribological properties [5].

Wear is one of the major forms of material deterioration, often limiting both the life and the performance of the industrial components and requiring frequent replacement of the components. Wear is affected by a variety of conditions, such as the type of lubrication, loading, speed, temperature, materials, surface finish, and hardness. Wear types include adhesive wear, abrasive wear, surface fatigue, fretting wear, erosive wear, and corrosive wear. It may be difficult to recognize the various damages types. However one type of damage is usually predominant [4-7].

Because the surface properties of cast irons do not match the performance requirements of the automotive industry, research is required to improve the surface properties of these materials, especially the wear resistance.

Three gas nitriding processes were used for the cast irons. All nitrided materials were examined using optical metallography, profilometry and microhardness to determine the nitrided case microstructure, surface roughness and through-thickness microhardness. Wear testing was performed for all nitrided cast irons using a ball (ceramic)-on-disc apparatus under lubricated conditions.

\section{Experimental details}

In the present research, austempered ductile iron (ADI), ductile iron (DI), and gray iron (GI) were treated using "Gas nitriding + nitrogen cooled down to $800^{\circ} \mathrm{F}$ " (Blue), "Gas nitriding + cooled down to $300^{\circ} \mathrm{F}$ " (Gray), and "Gas nitriding + oil quenched" (Oil). After the samples were nitrided, the nitrided layer was characterized using optical microscopy, Vickers microhardness testing, and SEM.

Samples for optical metallography were prepared according to ASTM E76899(2010) [8]. All sections examined were cross-sections perpendicular to the large flat nitrided surface. A CSM Micro-Hardness Tester (MHT) was used to measure the microhardness of the compound layer and diffusion zone. The load used was $0.025 \mathrm{~N}$. The measurements were carried out according to ASTM E384-11 [9]. Surface topographies of the nitrided surface layer were characterized by a two-dimensional profilometry tester (Mitutoyo SJ201), according to ASTM B946-11 [10].

For every material/nitriding combination, wear tests were done using a ballon-disc test apparatus according to ASTM G190-06 [11] and ASTM G13305(2010) [12] standards. They were carried out under lubricated conditions with a constant load of $10 \mathrm{lb}$ for 1 hour. The rotation speed was constant, $1.67 \mathrm{~m} / \mathrm{s}$ 
(700 rpm, wear track radius $22.75 \mathrm{~mm}$ ). The lubricant was light mineral oil. The coefficient of friction (COF) was recorded during the test. As the counterface in the wear test, the properties of ceramic ball are: nonporous high-alumina ceramic ball; Diameter: 5/16"; Hardness: 1700 Vickers. It should be emphasized that a "new" ceramic ball was used for each wear test.

A FEI Quanta 200 FEG SEM equipped with an EDS system was used to characterize the wear track and debris and to help identity the wear mechanisms. The wear performance was related to the nitride layer parameters.

\section{Experimental results and analysis}

In this section, results are presented for the microstructure of the cast irons, measurements of the compound layer thickness and diffusion zone depth, surface roughness, surface and through thickness microhardness of the nitrided layer and diffusion zone, and wear testing and characterization of worn materials. The wear performance is then correlated to the microstructure and mechanical properties.

\subsection{Metallography of core material of cast irons}

Optical micrographs of the core materials are shown in Figures 1(a)-(c). The microstructure of DI, Figure 1(a), primarily consists of a pearlite matrix and graphite nodules with surrounding ferrite (white phase). The microstructure of ADI, Figures 1(b), consists of an ausferrite matrix and graphite nodules. The microstructure of GI, Figure 1(c) consists of a pearlite matrix and graphite flakes.

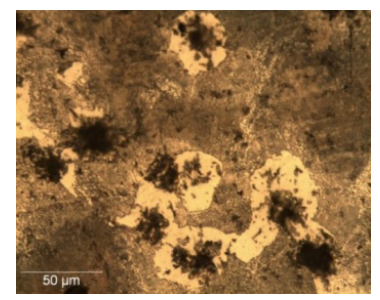

(a) Microstructure of DI

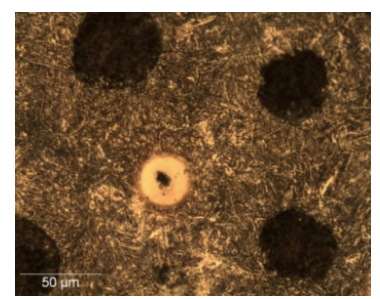

(b) Microstructure of ADI

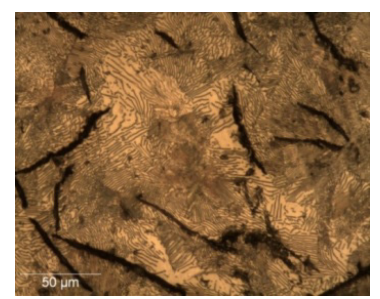

(c) Microstructure of GI

Figure 1: $\quad$ Microstructure of DI, ADI and GI.

\subsection{Metallography of nitrided layer}

Optical micrographs of the three cast iron samples treated using the three gas nitriding processes are presented in Figures 2-4 The microstructure of the nitrided case is composed of a thin compound layer (CL) with a diffusion zone (DZ) underneath. Good wear resistance is usually ascribed to this compound layer and the hardened diffusion zone [13].

The nitrided layers on DI (Figure 2), are relatively thin with little variability in thickness. The nitrided layers on ADI (Figures 3), show more variability in 
thickness. ADI treated using the Gray process is the thickest. In DI and ADI, the compound layers could enclose the graphite nodules. The morphology of the CL of GI is different from that for DI and ADI. For GI treated by either the Blue or Gray processes, the incorporation of the graphite flakes into the compound layer produces a very uneven surface (Figure 4).

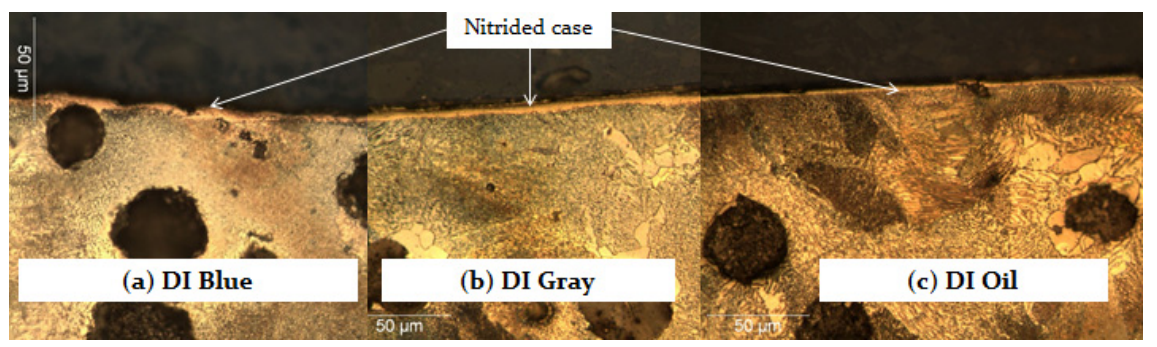

Figure 2: $\quad$ Microstructures of DI treated by Blue, Gray and Oil processes.

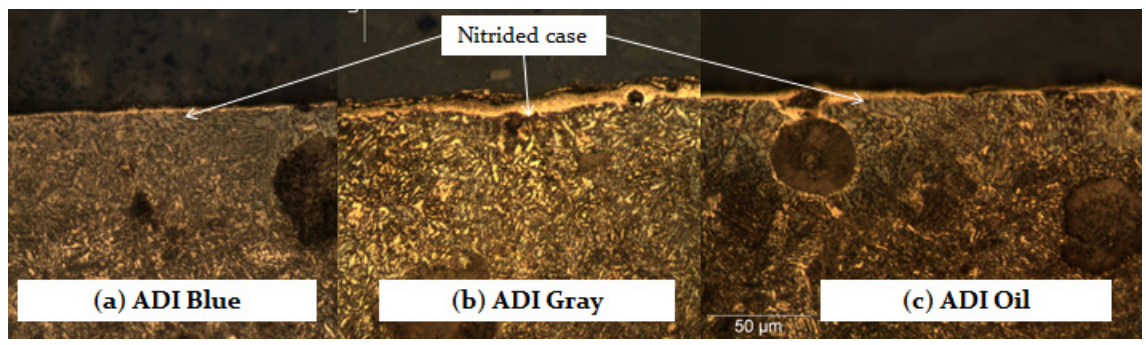

Figure 3: $\quad$ Microstructures of ADI treated by Blue, Gray and Oil processes.

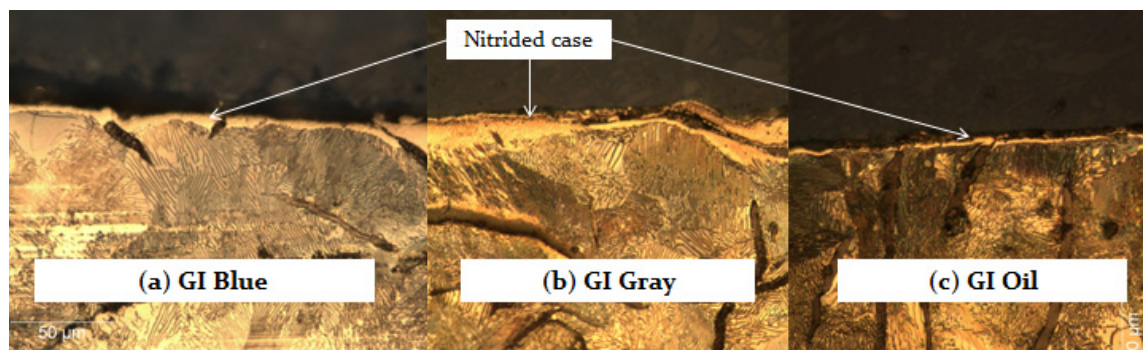

Figure 4: $\quad$ Microstructures of GI treated by Blue, Gray and Oil processes.

\subsection{Compound layer (CL) thickness and diffusion zone (DZ) depth}

Figures 5 and 6 present the results of the CL thickness and the DZ depth measurements, respectively. From Figure 5, it can be seen that GI processed using Gray nitriding has thickest compound layer, while ADI processed using 
Blue nitriding has the thinnest compound layer. In general, the greatest variability in CL thickness was shown by GI.

From Figure 6, it can be seen that the diffusion zone depth is largest for GI, which is same trend as for the compound layer. ADI generally has the smallest diffusion zone depth. Thus, the nitriding process that produced the highest compound layer thickness also produces larger diffusion zone depths.

Comparing the nitriding processes, Gray produced the thickest compound layer, followed by Blue, and then Oil. GI has the thickest compound layer on average, but the greatest variability in thickness. The Oil quench from gas nitriding produced the thinnest compound layer, and DI has thinnest compound layer. Gray gave the highest diffusion zone depth. GI has the highest DZ depth and ADI has the lowest DZ depth.

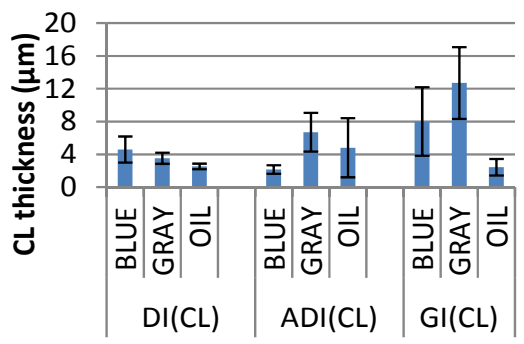

Figure 5: Compound Layer thickness.

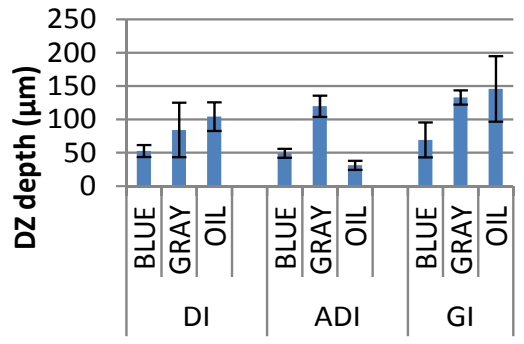

Figure 6: Diffusion Zone depth.

\subsection{Microhardness}

The microhardness measurements are presented in two sections, namely nitrided layer surface hardness and cross-sectional hardness. Measuring the microhardness of the nitrided layer is not an easy task because the thickness of the layer is of comparable dimensions to the indenter. The hardness is also influenced by the specific surface topography and graphite (soft phase) content in the area of the indent. The highest measured values are given in Table 1.

Table 1: $\quad$ Maximum values for surface microhardness of nitrided cast irons.

\begin{tabular}{cccc|ccc|ccc}
\hline & \multicolumn{3}{c}{ DI } & \multicolumn{3}{c}{ ADI } & \multicolumn{3}{c}{ GI } \\
\cline { 2 - 10 } & BLUE & GRAY & OIL & BLUE & GRAY & OIL & BLUE & GRAY & OIL \\
\hline HV & 2071 & 1913 & 2136 & 1767 & 1879 & 2251 & 1072 & 1017 & 1612 \\
\hline
\end{tabular}

The highest microhardness (2251HV) was measured for ADI treated using Oil quenching after gas nitriding. However, ADI treated using Blue and Gray processes and DI treated using Blue, Gray and Oil processes, have a high microhardness $(2000 \pm 250 \mathrm{HV})$. These high hardness levels should result in better 
wear performance. However, the microhardness for GI, no matter what nitriding treatment was applied, is very much lower, i.e. around $1000 \mathrm{HV}$, except for the Oil quench processing. This lower hardness is attributed to the graphite flakes which are incorporated into the compound layer (see for example Figure 4).

Figures 7(a)-(c) show the through-thickness microhardness measurements for DI, ADI, GI as plotted using Origin Pro software. A similar microhardness gradient is seen for all materials in all heat treated conditions. The microhardness of the compound layer is not reflected in these plots but rather the nitrogen distributions in the diffusion zone.
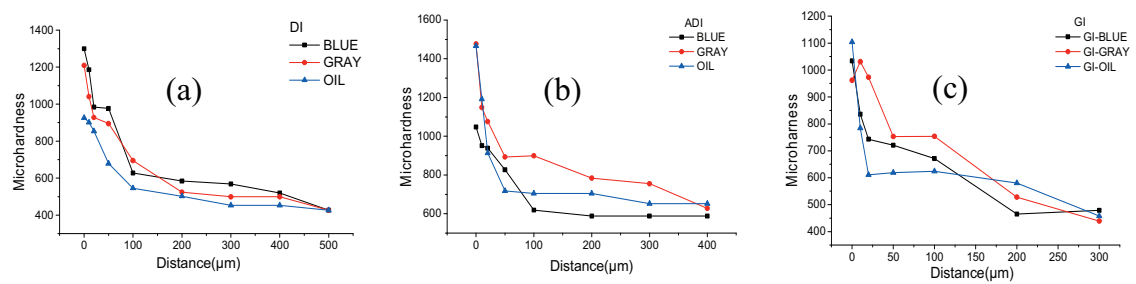

Figure 7: Microhardness of cross-sections.

\subsection{Surface roughness}

From the surface roughness results plotted in Figure 8, it can be seen that ADI treated using the Oil nitriding has lowest surface roughness, while GI treated using the Blue process has the highest surface roughness. GI treated using the Gray nitriding process showed the highest variability in roughness and a relatively high roughness value. In general, it can be seen that ADI has the lowest surface roughness.

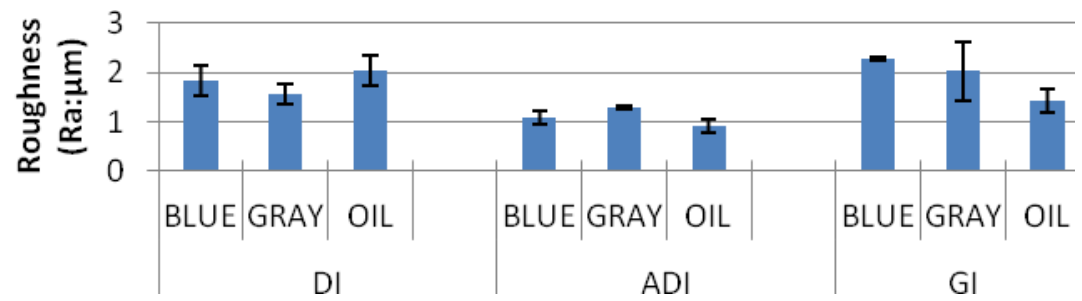

Figure 8: $\quad$ Surface roughness (Ra: $\mu \mathrm{m})$ after nitriding.

\subsection{Wear track width and depth measurements}

Good tribological properties of nitrided materials are usually ascribed to the compound layer. To characterize the enhancement of wear resistance derived from the nitriding treatments, one of the simplest, but effective, methods is to measure the dimensions (width and depth) of the wear track. The width and depth of the wear tracks measured using a combination of SEM and image 
analysis software (Image J), are given in Figure 9 for wear track width (WTW), and Figure 10 for wear track depth (WTD). Given that the counterface is a ceramic ball, the wear track width increases as wear proceeds, i.e. as the ceramic ball penetrates the nitride layer. Figure 9 shows that ADI processed using Oil quench nitriding has the best wear resistance, while GI processed using Gray nitriding has the worst wear resistance. DI processed using Gray and Oil nitriding process has better wear resistance, compared with DI processed using Blue. ADI, regardless of nitriding treatment has better wear resistance. The wear track depth results (Figure 10), lead one to similar conclusions.

We can see that the Oil nitriding process gave the best wear resistance of the three cast irons, and nitrided ADI exhibited the best performance.
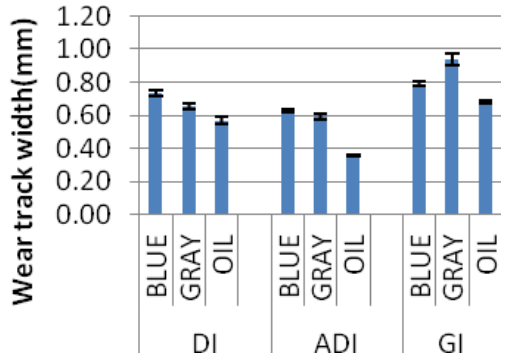

Figure 9: Wear track width.



Figure 10: Wear track depth.

\subsubsection{Comparison of wear track depth with CL thickness and DZ depth}

In order to investigate whether the compound layer are still protective after the wear test, and to know how much of the nitrided layer has been worn away, the wear track widths have been compared with the CL thickness and DZ depth. It was found that wear track depths are close to the values of the CL thickness, but are smaller than DZ depth. The difference between the CL thickness and wear track depth is given in Figure 11. For the duration of the wear test, the compound

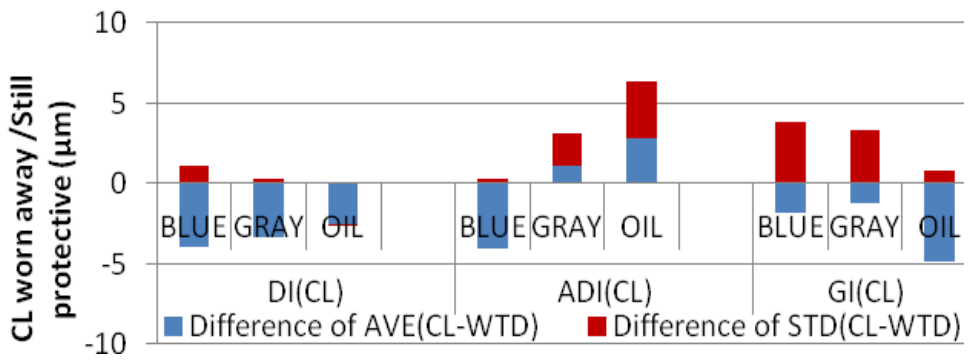

Figure 11: The difference between the CL thickness and wear track depth. 
layers on ADI nitrided using either the Gray or Oil nitriding process was still protective. For all other material/nitriding process combinations, the CL was completely worn away. Thus the wear protection mechanisms switch from CL protection to DZ protection.

\subsection{Coefficient of friction (COF)}

The coefficient of friction was recorded continuously during the wear test. It is mainly related to the surface roughness, compound layer parameters and the lubricated condition. As shown in Figures 12(a)-(b), the COF is always less than 0.045 indicating lubricated conditions. The COF either increased during the wear test because debris with hard particles accumulated in the wear track, e.g. DI-Gray, or decreased because the wear track was polished by the counterface ceramic ball and there was little or no debris.

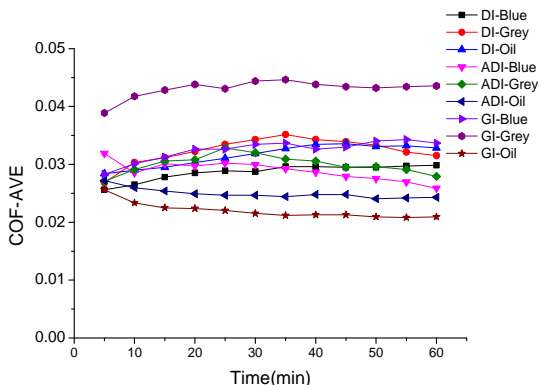

(a) COF (average) of cast irons

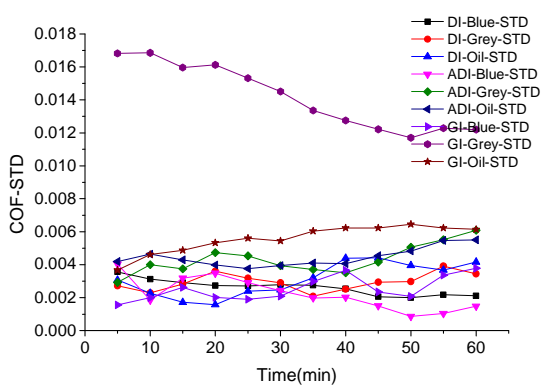

(b) The variability of the COF of cast irons

Figure 12: Coefficient of friction VS time plots for nitrided cast irons.

\subsection{SEM observations of wear tracks}

SEM was used to characterize the wear track morphology and debris to help identity the wear mechanisms. Figures 13(a)-(c) for DI indicate that all tracks look polished. Figures 14(a)-(c) for ADI indicate that wear tracks also look polished, but there is less debris than for DI. New pits were not as easily formed as in DI, but some pits still formed at the graphite nodules. Figures 15(a)-(c) for GI show the polished tracks. The amount of debris is more than that for DI or ADI. New pits are more easily formed at graphite flakes. Fewer pits were found for the oil quenched sample. This is consistent with the coefficient of friction (COF) data for GI (Figure 12), where the COF for GI-Blue and GI-Gray increase with time/sliding distance whereas GI-Oil shows a small decrease in COF with time. Wear mechanisms for these tests are predominantly adhesive wear, whereas abrasive wear could occur when debris accumulated. 

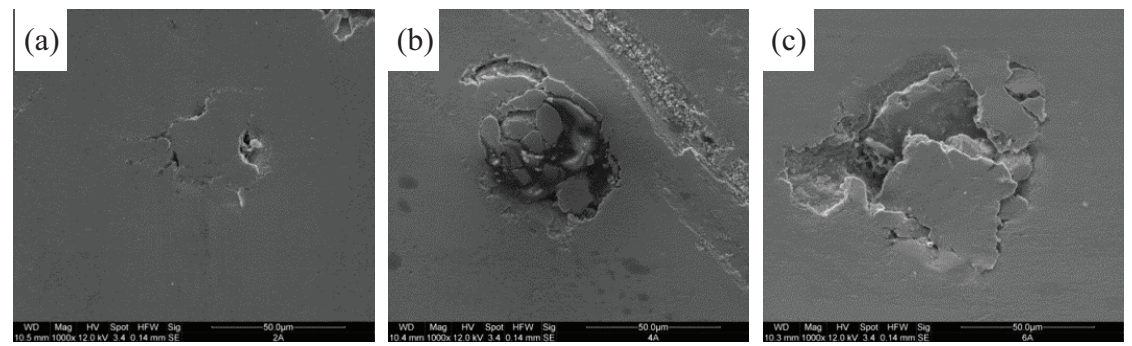

Figure 13: Wear track morphology as measured using SEM for (a) DI-Blue, (b) DI- Gray and (c) DI- Oil.
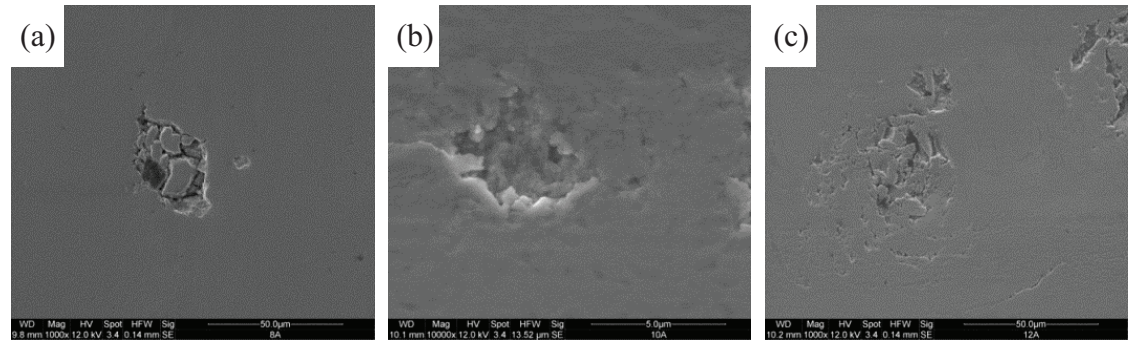

Figure 14: Wear track morphology as measured using SEM for (a) ADI-Blue, (b) ADI- Gray and (c) ADI- Oil.
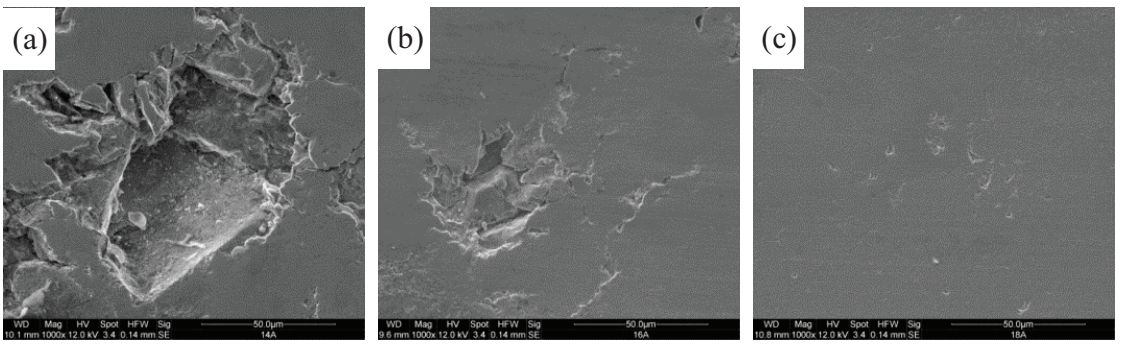

Figure 15: Wear track morphology as measured using SEM for (a) GI-Blue, (b) GI- Gray and (c) GI- Oil.

\subsection{Wear rate}

Wear rate is commonly calculated using two main formulas, based either on weight loss [14] or volume loss [15] $\mathrm{k}=\Delta \mathrm{V} / \mathrm{FS}$ (eqn. (1)), where $\mathrm{k}$ is the wear rate coefficient, $\Delta \mathrm{V}$ wear volume loss, $\mathrm{F}$ the normal load, and $\mathrm{S}$ the total sliding distance. The second is more widely used and more applicable to this study because of the different densities of the materials used in this study. In this study: 


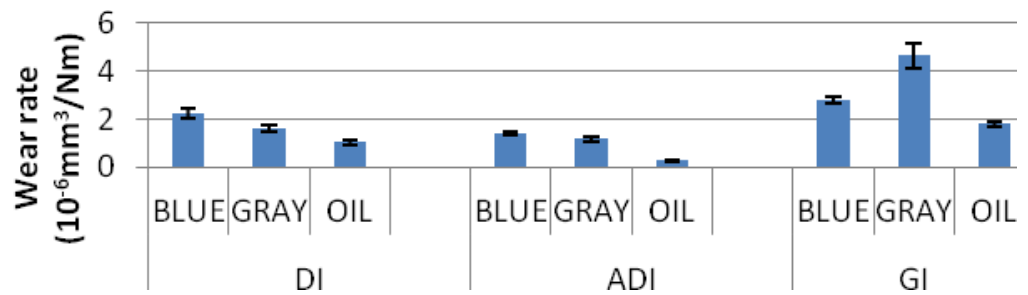

Figure 16: Average wear rate of the nitrided cast irons.

$\mathrm{F}=44.45 \mathrm{~N}$ (10lbs); $\mathrm{S}=6003.58 \mathrm{~m} ; \mathrm{FS}=266871.6 \mathrm{Nm}$. The calculated wear rates of the nitrided cast irons and Isonited 4140 steel are shown in Figure 16.

ADI treated using Oil nitriding process has the lowest wear rate. This is attributed to the optimum CL thickness, CL morphology, the adherence of the compound layer to the substrate, high hardness, and low surface roughness. GI treated using Gray nitriding process has the highest wear rate. Although the compound layer is thicker, it is softer and less adherent and has a higher surface roughness. The properties of the CL on ADI (Oil) and GI (Gray) are compared in Table 2.

Table 2: $\quad$ Comparison of ADI (Oil), the best wear resistance, with GI (Gray), the poorest wear resistance.

\begin{tabular}{|l|l|l|}
\hline & ADI (Oil) & GI (Gray) \\
\hline Compound Layer Thickness & $\sim 5 \mu \mathrm{m}$, little variability & $\sim 12 \mu \mathrm{m}$, large variability \\
\hline Morphology & $\begin{array}{l}\text { CL could incorporate } \\
\text { graphite nodules }\end{array}$ & $\begin{array}{l}\text { Graphite flakes } \\
\text { incorporated into CL }\end{array}$ \\
\hline Adherent & Yes & Partially \\
\hline Max. Surface Hardness(HV) & 2251 & 1017 \\
\hline Surface Roughness $(\mu \mathrm{m})$ & $0.93 \pm 0.13$ & $2.03 \pm 0.60$ \\
\hline COF & $0.025-0.03$ & 0.04 \\
\hline
\end{tabular}

The relationship between wear rate and roughness and microhardness of nitrided surface are shown in Figures 17 and 18. The linear fitting functions of wear rate against roughness and microhardness of nitrided surface are given in Equations (2) and (3). For Equation (2), the Residual Sum of Squares (RSS) is $7.27864^{-12}$, which indicates good linear relationship between wear rate and roughness. For Equation (3), the Residual Sum of Squares (RSS) is $3.5673^{-12}$, which also indicates good linear relationship between wear rate and microhardness.

$$
\begin{gathered}
\text { Wear rate }\left(10^{-6} \mathrm{~mm}^{3} / \mathrm{Nm}\right)=1.79 \mathrm{Ra}-1.00 \\
\text { Wear rate }\left(10^{-6} \mathrm{~mm}^{3} / \mathrm{Nm}\right)=6.14-0.0024 \mathrm{HV}
\end{gathered}
$$




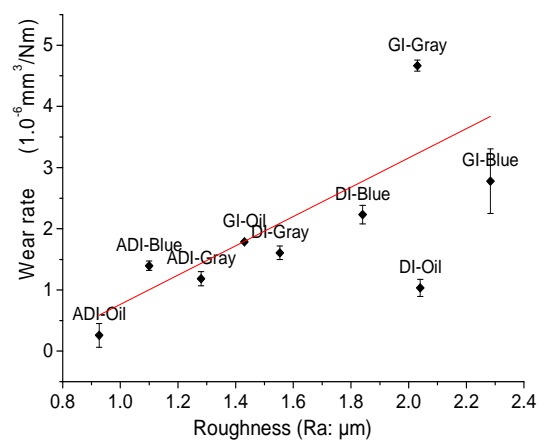

Figure 17: Function of wear rate against surface roughness.

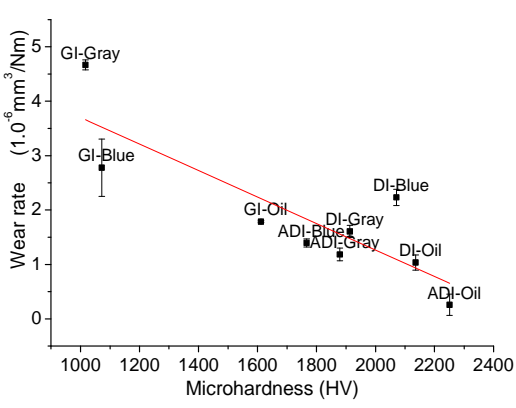

Figure 18: Function of wear rate against microhardness of nitrided surface.

\section{Conclusions}

The main conclusions were:

1. The COF for all cast irons in all nitrided conditions was small $(<0.045)$, reflecting the lubricated test conditions (fully flooded or starved lubrication).

2. Small differences were seen in the variation of COF with time. A very small decrease in COF with time is interpreted as being related to polishing of the wear track. A small increase in COF with time is thought to be related to accumulation of debris in the wear track. When the COF stays essentially constant with time, it is considered that the polishing of the wear track is "balanced" by accumulation of some debris.

3. The overall wear rate is shown to be primarily dependent on two parameters, namely the surface roughness and surface microhardness of the nitrided material. The wear rate decreased with increasing surface microhardness and decreasing surface roughness.

4. The best wear performance is shown when the wear track does not fully penetrate the compound layer. Such behaviour was seen for ADI processed using the Gray and Oil nitriding processes. These processes produced a

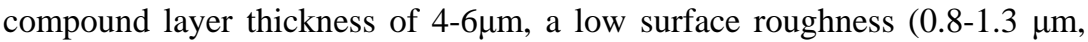
$\mathrm{Ra})$ and a high surface microhardness (1800-2200 HV) reflecting a dense and adherent compound layer. The compound layer thickness in GI was larger (up to $12 \mu \mathrm{m}$ ) but it was not as hard (1000-1500 HV) and the roughness was higher (up to $2.5 \mu \mathrm{m}, \mathrm{Ra}$ ) and showed the greatest variability. 


\section{References}

[1] Davis JR. Cast irons. Materials Park, OH: ASM International; 1996.

[2] Martins R, Seabra J, Magalhães L. Austempered ductile iron (ADI) gears: Power loss, pitting and micropitting. Wear. 2008; 264:838-49.

[3] Dhanapal P, Nazirudeen SSM. A Study of the Structure and Properties of High-Strength Bainite-Carbide Cast Iron with Globular Graphite. Metal Science and Heat Treatment. 2012; 53:578-83.

[4] Sahin Y, Durak O. Abrasive wear behaviour of austempered ductile iron. Materials and Design. 2007; 28:1844-50.

[5] Xie KY, Breen AJ, et al. Overcoming challenges in the study of nitrided microalloyed steels using atom probe. Ultramicroscopy. 2012; 112:32-38.

[6] Colangelo VJ, Heiser FA. Analysis of metallurgical failures. 2nd ed. New York: Wiley; 1987.

[7] Allen C, Ball A. A review of the performance of engineering materials under prevalent tribological and wear situations in South African industries. Tribology International. 1996; 29:105-16.

[8] ASTM. E768-99(2010) Standard Guide for Preparing and Evaluating Specimens for Automatic Inclusion Assessment of Steel. 2010.

[9] ASTM. E384-11e1 Standard Test Method for Knoop and Vickers Hardness of Materials. 2012.

[10] ASTM. B946-11 Standard Test Method for Surface Finish of Powder Metallurgy (P/M) Products. 2011.

[11] ASTM. G190-06 Standard Guide for Developing and Selecting Wear Tests. 2007.

[12] ASTM. G133-05(2010) Standard Test Method for Linearly Reciprocating Ball-on-Flat Sliding Wear. 2010.

[13] Abisset S, Maury F, Feurer R, Ducarroir M, Nadal M, Andrieux M. Gas and plasma nitriding pretreatments of steel substrates before CVD growth of hard refractory coatings. Thin Solid Films. 1998; 315:179-85.

[14] Wang QL, Huang CH, Zhang L. Microstructure and Tribological Properties of Plasma Nitriding Cast CoCrMo Alloy. Journal of Materials Science and Technology. 2012; 28:60-66.

[15] Singh K, Krishnamurthy N, Suri AK. Adhesion and wear studies of magnetron sputtered NbN films. Tribology International. 2012; 50:16-25. 